\title{
mssaico
}

\section{Políticas culturais}

\section{em museus:}

Panoramas e perspectivas do cenário brasileiro

\section{Mélodi Ferrari ${ }^{1}$}

\section{Cultural Policies} and Museums in Brazil: Trends and outlooks

http://dx.doi.org/10.12660/rm.v7n11.2016.64782

\footnotetext{
${ }^{1}$ Especialista em Economia da Cultura e graduanda em História da arte na Universidade Federal do Rio Grande do Sul. E-mail: melfferrari@hotmail.com
} 


\section{Resumo:}

O artigo proposto apresenta um breve resumo histórico das políticas culturais implementadas no Brasil, buscando compreender como elas influenciaram no campo museal. Além disso, com vista no cenário atual, analisa-se uma proposta de atuação baseada no modelo americano de gestão de instituições culturais que possa ser implantada visando a ampliação do conceito de museus como instituição formadora da identidade cultural brasileira, em toda sua pluralidade.

Palavras-chave: Economia da Cultura, Museus, Políticas Culturais.

\section{Abstract:}

This article aims to present a brief historic outlook of the cultural policies implemented in Brazil, in search of understanding how they influenced the museum landscape. Furthermore, in regards to the current scenario, it analyzes a proposal of museum functionality, based on the American model of managing cultural institutions, that can be implemented with the goal of amplifying the concept of museum as an institution that plays a part in forming Brazilian cultural identity, in all its plurality.

Keywords: Cultural Economy, Museums, Cultural Policy. 


\section{Introdução}

Mausoléus, depósito de velharias, vácuo de profissionais qualificados, péssimas condições de infraestrutura, desinteressantes. É com esses adjetivos pejorativos que a população costuma descrever os museus brasileiros. Mas afinal, como e por que chegamos a essa situação? Instituições museológicas na Europa e Estados Unidos são reconhecidas internacionalmente pela qualidade de acervo e programação, e atraem milhões de visitantes anualmente. Casos como o Louvre em Paris, ou o MoMA em Nova lorque, são importantes atrativos turísticos que movimentam a economia local e divulgam a identidade nacional. $O$ que impede que esse panorama se desenvolva no Brasil?

De acordo com dados do relatório "Museu em Números"1 , o país possui mais de 3 mil unidades museológicas, dentre essas $67,2 \%$ são geridas pela esfera pública, cerca de $5,7 \%$ encontram-se fechadas e somente $22,3 \%$ declaram possuir fonte de recursos próprios. Se 0 papel de financiador da cultura pertence ao governo, seria ele o responsável pela situação vigente? Assim, o enfoque desse artigo não será a demanda por cultura, mas sim a oferta. A questão central é compreender, através de uma breve análise histórica, qual o papel e o entendimento que o Estado tem acerca da cultura, e como isso afeta a gestão dos equipamentos culturais, principalmente os museus. Em um país com um contexto político e social como o nosso, que sofreu períodos de colonização e de ditaduras, as políticas públicas funcionam como estabilizador e propagador da autoridade vigente. Os últimos vinte anos que vivemos são importantes para compreendermos a mudança desse paradigma. A ampliação do entendimento do conceito de cultura e a criação de mecanismos para a desburocratização do campo museal serão pontos discutidos no artigo. Como exemplo, apresento o caso do Museu de Arte do Rio de Janeiro (MAR), um dos primeiros no país a seguir o modelo de Organização Social, administrado através de parceria público-privada que vem recebendo um público considerável e exibindo exposições de qualidade.

\section{Políticas Culturais e Financiamento da Cultura}

Como ponto de partida, utilizaremos o conceito de "cultura" apresentado por Coelho (1997), que utiliza a definição provinda da antropologia, entendendo ser aquela que melhor se enquadra ao objeto de estudo em questão - políticas culturais contemporâneas. Para o autor, cultura diz respeito a tudo aquilo que resulta da produção humana, seja ela material ou simbólica, em um processo sociológico de constituição. Ou seja, cultura é manifestação popular produzida com ou sem a intervenção do Estado. Contudo, o modo como a administração governamental trata o tema é relevante para ampliar e difundir a cultura. As políticas culturais têm função de desenvolver o setor, fortalecendo a produção, formação, difusão e consumo da cadeia cultural, articulando planos, estratégias e diagnósticos que corrijam as falhas nesse sistema (BARBALHO, 2005). Segundo Botelho

\footnotetext{
${ }^{1}$ INSTITUTO BRASILEIRO DE MUSEUS (IBRAM). Museus em Números. Brasília: Instituto Brasileiro de Museus, 2011; v. 1-2.
} 
(2001), o financiamento é determinado pela política, e não ao contrário; assim, o Estado possui papel fundamental de regulamentador desse processo. Para a compreensão do funcionamento das políticas públicas culturais no Brasil, faz-se necessária uma breve revisão histórica acerca do tema.

As intervenções na área cultural podem ser observadas desde o período colonial no Brasil. Segundo Rubin (2012), quando o Estado, ainda sob formato de monarquia, persegue as culturas indígenas e africanas e proíbe a instalação da imprensa nacional e a criação de universidades, está indiretamente interferindo na política cultural, apesar de tratar-se de tempo anterior a essa caracterização. Sob esse contexto, observa-se uma doutrina autoritária, utilizada para preservar e legitimar uma cultura dominante. O panorama não irá mudar nem com a Independência do país nem com o advento da República.

Será somente na década de 30, com a ascensão de Getúlio Vargas ao poder e a criação do Estado Novo, que as políticas culturais oficialmente tomam forma. Fatores como a industrialização, urbanização e a construção de um Estado nacional centralizado favoreceram a criação das primeiras organizações públicas voltadas para a preservação das identidades culturais. Dentre elas se destaca o Serviço do Patrimônio Histórico e Artístico Nacional (SPHAN) ${ }^{2}$ e outros órgãos destinados a regulamentar áreas específicas da cultura como o Serviço Nacional de Teatro (SNT), o Instituto Nacional do Livro (INL) e o Instituto Nacional do Cinema Educativo (INCE), todos veiculados ao Ministério da Educação e Saúde durante a gestão de Gustavo Capanema. Contudo, esses mecanismos ainda possuíam a visão de cultura caracterizada pelo autoritarismo. Naturalmente, pelo caráter totalitário do instituto, esse meio era orquestrado pelo Departamento de Informação e Propaganda (DIP), que articulava censuras às manifestações culturais, próprias de qualquer ditadura. O Estado utilizava a cultura como instrumento para a construção de uma nação, "valorizando o nacionalismo, a brasilidade, a harmonia entre as classes sociais, o trabalho e o caráter mestiço do povo brasileiro" (RUBIN, 2012, p. 33), moldando o discurso da forma com que melhor the conviesse. No período de redemocratização, não houve significativas intervenções governamentais no que tange políticas culturais.

Em 1964, apesar da intervenção militar no país, as políticas relacionadas à cultura não sofrem grandes transformações, inicialmente; o momento político atribulado fertilizou a articulação de diversos segmentos de cultura popular nos variados cantos do Brasil, como os centros populares de cultura (CPC) e o movimento dos estudantes nas universidades. Porém, quanto mais duro tornava-se o regime, maior era a censura e opressão a esses segmentos, e crescia a imposição de uma cultura midiática sofisticada e reprodutora da ideologia oficial (RUBIN, 2012). No período denominado abertura, sob o governo de Geisel e Figueiredo, a produção cultural volta a ter papel essencial como formadora da identidade nacional inclusive, houve uma ampliação dos investimentos na área, a criação da Fundação Nacional

\footnotetext{
${ }^{2}$ O SPHAN posteriormente se transformará no Instituto do Patrimônio Histórico e Artístico Nacional (IPHAN), existente até os dias de hoje que é uma autarquia do Governo do Brasil, vinculada ao Ministério da Cultura, responsável pela preservação do acervo patrimonial tangível e intangível do país.
} 
de Artes (FUNARTE) 3 e do primeiro Plano Nacional de Cultura (PNC) ${ }^{4}$, em 1975. Fernandes (2013) conclui que essas articulações foram importantes, pois marcaram uma mudança na destinação dos recursos para a cultura: se, antes, a prioridade era a preservação do patrimônio histórico, agora, passam-se a incentivar atividades culturais. Esses movimentos culminaram na autonomia do Ministério da Cultura, criado como órgão independente em 1985, já no governo Sarney.

Uma importante medida tomada pelo Ministério da Cultura foi a criação da Lei Sarney. Para Rubin (2012), essa iniciativa caracterizou um movimento paradoxal, pois, ao mesmo tempo em que diversos órgãos eram criados para centralizar a administração da produção cultural, a lei propunha o financiamento indireto da área. O Estado diminui sua participação, e estabelece que as verbas sejam buscadas no mercado. Inaugura-se, assim, a forma de financiamento cultural, com incentivos fiscais. Segundo Durand (2013), a Lei Sarney sofreu diversas críticas, e até hoje seus resultados quantitativos não foram propriamente divulgados e avaliados. Além disso, a lei não distinguiu as iniciativas culturais, sem processo de aprovação técnica, dos projetos propriamente ditos; assim, não houve controle de onde os recursos estavam sendo investidos, podendo-se financiar espetáculos puramente comerciais. O aprimoramento dessa lei deu-se no governo de Fernando Collor de Melo, realizado em 1991, dentro do Programa Nacional de Apoio à Cultura (Pronac) ${ }^{5}$, com a chamada Lei Rouanet - um dos principais mecanismos de financiamento cultural utilizados no país até os dias de hoje.

Essas propostas foram decorrentes da onda neoliberal surgida a partir da década de 80. A política de enxugamento do Estado pela redução dos investimentos nas áreas sociais impulsionou o governo a revisar as políticas públicas, atingindo, principalmente, a cultura. A problemática atual relativa ao incentivo cultural no Brasil é a não-revisão dessa proposta desatualizada, representada pela vigência praticamente inalterada da lei Rouanet. Para Durand, a lei de incentivo fiscal não muda a dependência do setor pelos recursos públicos, pois o mecenato aqui imposto tornou-se um mero repasse de verbas públicas. Assim, os setores de marketing das empresas atuam como distribuidores dos patrocínios da área cultural, privilegiando somente um segmento seguro de mercado, no qual projeta-se retorno pecuniário aos seus investimentos.

Os problemas existentes hoje no Brasil, quanto à captação de recursos via leis de incentivo fiscal, relacionam-se ao fato de produtores culturais de grande e pequeno portes lutarem pelos mesmos recursos, num universo ao qual se somam as instituições públicas depauperadas, promovendo uma

\footnotetext{
${ }^{3}$ Órgão existente até hoje responsável pelo desenvolvimento de políticas públicas de fomento às artes visuais, à música, ao teatro, à dança e ao circo.

${ }^{4}$ O PNC é um conjunto de diretrizes estratégicas formuladas a partir de amplos debates com a sociedade, cujo fim é o de articular sistemicamente atores, ações e políticas públicas de cultura.

${ }^{5}$ O PRONAC prevê o financiamento por três vias: o direto, através do Fundo Nacional de Cultura (FNC) previsto por editais; o indireto, renúncia fiscal; e o misto, Fundos de Investimento Cultural e Artístico (Ficart) até hoje não implantado, que prevê recursos privados para a realização de projetos artísticos com participação dos investidores nos possíveis lucros.
} 
concorrência desequilibrada com os produtores independentes (BOTELHO, 2001, p. 78).

Contudo, a Constituição de 1988 reserva uma seção específica para a Cultura: "o Estado garantirá a todos o pleno exercício dos direitos culturais e acesso às fontes da cultura nacional, e apoiará e incentivará a valorização e a difusão das manifestações culturais" (BRASIL, 1988, artigo 215). Além disso, firmam-se como patrimônio cultural brasileiro bens de natureza material e imaterial, valorizando memórias e identidades de diferentes grupos formadores da nação. Ou seja, responsabiliza-se o Estado pela produção cultural nacional, em sua pluralidade de manifestações.

Foi a partir de 2003, com a ascensão do Partido dos Trabalhadores ao poder, que novas diretrizes para a cultura foram aplicadas. O presidente Luis Inácio Lula da Silva nomeia como Ministro da Cultura o artista baiano Gilberto Gil, cuja marca como gestor, em suas próprias palavras, seria a abrangência. Deste modo, prioriza-se o diálogo com a sociedade maneira de combater o unilateralismo vigente na área, e ampliar o escopo de políticas culturais democráticas na área da cultura (RUBIN, 2012).

Além disso, adota-se o conceito antropológico de cultura, fundamental para esse novo momento. Segundo essa concepção, não só os artistas, mas todos os indivíduos são produtores de cultura, e é através das suas relações interpessoais que constroem-se sentidos, valores e identidades, permitindo a estabilidade social. Direcionando as políticas culturais a partir desse caráter abrangente, coloca-se em foco a diversidade de culturas existente no país, dando voz às manifestações populares, de gênero, afro-brasileiras, indígenas, dentre outras.

Embora as duas dimensões - antropológica e sociológica - sejam igualmente importantes, do ponto de vista de uma política pública, exigem estratégias diferentes. Dadas suas características estruturais, devem ser objeto de uma responsabilidade compartilhada dentro do aparato governamental em seu conjunto. A distinção entre as duas dimensões é fundamental, pois tem determinado o tipo de investimento governamental em diversos países, alguns trabalhando com um conceito abrangente de cultura e outros delimitando o universo específico das artes como objeto de sua atuação. A abrangência dos termos de cada uma dessas definições estabelece os parâmetros que permitem a delimitação de estratégias de suas respectivas políticas culturais. (BOTELHO, 2001, p. 74)

Na mesma linha, outro importante mecanismo construído foi o Sistema Nacional de Cultura (SNC), que prevê a gestão dos investimentos na área de forma transparente, democrática e inclusiva; as políticas culturais devem, assim, serem realizadas de forma participativa, abrangendo as três esferas governamentais - município, estado, nação. Também, expressa-se respeito às inúmeras culturas que compõem a matiz nacional. O SNC é regulamentado pelo Conselho Nacional de Política Cultural (CNPC), órgão colegiado, integrante do Ministério da Cultura, ao qual compete a formulação de políticas públicas para a cultura a partir da articulação de diferentes níveis do governo e da sociedade civil 
organizada. Seus membros são acadêmicos, empresários e representantes do setor artístico.

Também, em 2013, o MinC instituiu o Programa de Cultura do Trabalhador, cujo principal projeto é o Vale Cultura. Trata-se de um benefício no valor de 50 reais mensais destinado aos trabalhadores que recebem até cinco salários mínimos. O vale pode ser utilizado em serviços e produtos culturais como teatro, exposições, cinema, concertos, shows e compra de livros, CDs e DVDs. As empresas que se cadastrarem no programa podem abater o valor até $1 \%$ do imposto de renda devido. O objetivo desse programa é colocar a decisão de escolha no que tange o consumo da cultura nas mãos do trabalhador, incentivando o acesso às práticas culturais, visando a democratização do setor.

Até então, o Partido dos Trabalhadores, estava realizando mudanças graduais no setor cultural. Contudo, devido ao panorama nacional o qual a cultura não é mais prioridade, o futuro do campo é incerto. Botelho, em 2013, afirmou que uma das principais limitações das políticas culturais públicas no Brasil é o fato delas nunca alcançarem, por si próprias, a dimensão antropológica.

\section{Os Museus Brasileiros e o Modelo Americano}

O campo museal passou por diversas transformações nas últimas décadas. No início do século $X X$, os museus foram criticados por representarem somente a história oficial e o patrimônio das elites. Nos anos 60, com o advento da indústria cultural, decretou-se a sua morte. Contudo, a partir do movimento denominado Nova Museologia, seu conceito amplia, o museu se consolida como importante instrumento de difusão e democratização cultural.

Os museus conquistaram notável centralidade no panorama político e cultural do mundo contemporâneo. Deixaram de ser compreendidos por setores da política e da intelectualidade brasileira apenas como casas onde se guardam relíquias de um certo passado ou, na melhor das hipóteses, como lugares de interesse secundário do ponto de vista sociocultural. Eles passaram a ser percebidos como práticas sociais complexas, que se desenvolvem no presente, para o presente e para o futuro, como centros (ou pontos) envolvidos com criação, comunicação, produção de conhecimentos e preservação de bens e manifestações culturais. Por tudo isso, o interesse político nesse território simbólico está em franca expansão (MINC, 2010, p. 24).

No Brasil, a partir da década de 30, foram criados diversos museus com o intuito de valorizar a identidade nacional, seguindo os parâmetros das políticas culturais propostas pelo Estado Novo. Esse movimento resultou em um esforço para o desenvolvimento do setor. Nas décadas seguintes, impulsionado pelo período pós-Segunda Guerra, houve a articulação para a criação do Conselho Internacional de Museus (ICOM) consolidando a área museológica inclusive no Brasil, país membro dessa organização desde sua fundação. 
Segundo Santos (2004), os regimes ditatoriais da década de 70 na América Latina fomentaram as discussões acerca do papel do museu na sociedade, refletindo na multiplicação dos museus na década de 80 . "O aumento dos museus locais representaria a abertura de lugares de convívio, dando espaço tanto para o fortalecimento de autoestima e criatividade, como para manifestações solidárias" (2004, p. 71). Enquanto no cenário mundial - Europa e EUA - buscava-se o processo de comercialização de narrativas e dos elementos simbólicos, captando grandes investimentos e atraindo o maior número de visitantes possíveis, no Brasil a situação era diferente. O modelo neoliberal pouco contribuiu para o desenvolvimento do setor, pois aliou a infraestrutura estatal precária com o modelo de incentivo fiscal, ocorrendo uma centralização dos museus nas capitais que possuíam maiores investimentos.

Como já mencionado, o campo cultural rearticulou-se no Brasil nos anos 2000, e novas perspectivas para os museus foram propostas. Na administração cultural de Gilberto Gil, em 2003, previsto dentro do Sistema Nacional de Cultura, foi lançado o documento que estipulou o processo de construção da Política Nacional de Museus. Dentro de suas diretrizes está a criação do Sistema Brasileiro de Museus (SBM), o fomento de capacitação de recursos humanos para área, informatização, melhorias da infraestrutura, fomento para aquisição e preservação de acervo e a criação do Cadastro Nacional de Museus.

O SBM tem como objetivo desenvolver e promover as diversas instituições museológicas existentes no país. A iniciativa representa uma importante ferramenta de articulação da Política Nacional de Museus, pois consolida e amplia a rede de parcerias institucionais, promovendo a capacitação de servidores e divulgando ações regionais em nível nacional. Atuando em conjunto com o SBM, o Cadastro Nacional de Museus estabelece uma plataforma unificada com amplitude nacional dos museus, formando o primeiro censo museológico. Essa iniciativa é fundamental para conhecer e mapear as diferentes instituições existentes pois, a partir desse cenário, é que as políticas culturais da área serão construídas.

Em 2009 foi criado o Instituto Brasileiro de Museus (IBRAM), uma autarquia vinculada ao Ministério da Cultura. Atua em substituição ao Iphan nos direitos, deveres e obrigações relacionados aos museus federais. O órgão tornou-se responsável pela Política Nacional de Museus, implementando melhorias no setor - aquisição e preservação dos acervos, aumento de arrecadação e da visitação. O Ibram representa um marco histórico, pois é fruto das articulações culturais que ocorrem no país e da nova formulação de conceito ampliado de museu, valorizando seu papel na consolidação das diversas culturas nacionais. Além disso, agora, as instituições museais possuem órgão próprio de regulamentação, fiscalização e fomento ao turismo na área.

Apesar das articulações a nível político, a situação da maioria dos museus no Brasil ainda é precária. O próprio MinC, através do "Relatório de Gestão das Políticas de Museus" especifica alguns fatores que contribuem para o cenário atual: precariedade no nível jurídico e administrativo, falta de fomento aos investimentos, má gestão, falta de público e a nãovalorização das pesquisas e dos acervos. Aqui, não se pretende abordar as questões relativas a público e pesquisa, mas sim o caráter gerencial e a captação de recursos, pois acredita-se 
que somente com investimento em ações significativas o museu será um espaço vivo, aberto e de diálogo com a sociedade.

Como já explicitado, no Brasil, o Estado tem o papel de financiador da cultura, com base no modelo francês. Contudo, não é assim que funciona na prática; as leis de incentivo, como a Lei Rouanet, representam uma grande parcela do investimento: $25,7 \%$, segundo dados do Museu em Números. Para Abreu (2010), apesar da iniciativa privada ter assumido o papel de investidor da cultura, o apoio se dá em situações pontuais, onde visa-se retorno em termos de imagem institucional - diferente de uma cultura de mecenato, que se baseia na noção de filantropia (investimento em benefícios sociais que não necessariamente necessitam de uma contraposta de benefício fiscal).

Quando tratamos da dependência da política de marketing das empresas, temos instituições com pouca autonomia, que demandam a captação de patrocínios de curto prazo, em geral a cada temporada, a cada exposição, a cada nova turnê de uma orquestra ou a cada novo ciclo de um programa educativo (SCHULER, 2012, p. 130).

O modelo americano baseia-se no oposto do francês: a opinião pública coloca-se contra o patrocínio governamental das artes e a política de mecenatos é extremamente forte. Contudo, não se pode dizer que não haja a intervenção do Estado; há políticas culturais muito bem definidas para esse sistema funcionar6. Abreu (2010) irá identificar duas concepções que embasam essa sistemática: primeiro, historicamente, houve a criação de organizações e associações que servem como fiscalizadoras e que acompanham as ações do poder público; e, segundo, há forte tradição de envolvimento do empresariado e da sociedade civil, que veem a importância do investimento em áreas culturais, a fim de valorizar a identidade nacional.

Uma das principais estratégias utilizada nos EUA foi a criação do National Endowment for the Arts, que serve para fomentar a sustentabilidade financeira de instituições culturais, além de financiar pesquisas, incentivar o intercâmbio de artistas e profissionais da área (DURAND, 2013). Segundo Schuler os endowments são:

Fundos permanentes de aplicação financeira, que uma determinada organização faz crescer continuamente, apenas retirando (para o cumprimento dos objetivos da instituição) os resultados líquidos obtidos, isto é, o rendimento alcançado menos a inflação do período de apuração. $O$ foco é fazer o fundo crescer consistentemente ao longo do tempo, de modo que os resultados por ele gerados possam custear uma parcela recentemente significativa do orçamento da organização $(2012$, p. 131).

Ainda segundo o autor, o fundo patrimonial, como é denominado no Brasil, é uma

\footnotetext{
${ }^{6}$ Não existe nenhuma estrutura administrativa semelhante ao Ministério da Cultura nos EUA. Contudo, há uma multiplicidade de agências reguladoras que são fiscalizadas por comitês do poder legislativo e respondem pelos segmentos políticos. A principal no ramo cultural está o National Endowment for the Art. (DURAND, 2013).
} 
garantia de permanência e ampliação contínua dos serviços culturais de um museu. Sabendo antecipadamente a fatia de orçamento que poderá ser resgatada, é mais fácil gerir os recursos e estipular quais são as prioridades a serem tomadas, e o planejamento entra em foco. Normalmente, o endowment de certa instituição é constituído por doações de pessoas físicas, possuidoras de grandes fortunas. No caso americano, os endowments constituem-se pelo forte sentimento filantrópico que existe: o objetivo, pessoal, é a garantia de uma herança cultural que será preservada. Ou seja, a doação tem um caráter perpétuo, vinculada ao dever social.

Durand questiona a existência do mecenato no Brasil. Para ele, o modelo vigente de redução fiscal faz com que as empresas se tornem as principais financiadoras, e não o empresário e sua família. Para Abreu, o Estado já adotou alguns incisos claros com respeito ao mecenato no país, como instituir a doação incentivada - ou seja, a transferência, sem finalidade promocional, de recursos financeiros para projetos culturais, previamente aprovados pelo MinC. Mas, segundo Botelho, a real dificuldade está em criar a cultura de compromisso das elites com a responsabilidade sócio/cultural.

A escolha do indivíduo é por aquilo que lhe é mais próximo, por aquilo com o qual mais se identifica e pelo qual ele se dispõe não só a investir, mas também a lutar. Por isso o investidor individual é a fatia que o Brasil precisa conquistar na ampliação dos parceiros do jogo nesta articulação de esforços que, cabe insistir, têm de ser articulados por uma política pública criteriosamente escolhida (BOTELHO, 2001, p. 79).

No Brasil, ainda não há nenhum modelo de lei para endowments. Schuler (2012) destaca, também, que, além do problema do financiamento, há a questão da política de gestão dos museus. A rede brasileira é composta por museus que são, em sua maioria, geridos por e como órgãos públicos. Assim, os museus brasileiros financiam-se mediante recursos orçamentários e editais das leis de incentivo fiscal. O Estado repassa apenas os recursos mínimos para a manutenção e administração desses institutos, mas a função-fim dos museus é negligenciada. Ou seja, projetos educativos, museografia e exposições têm seus aportes financeiros dependentes de iniciativas políticas, em cada uma das esferas de governo. Mesmo os museus privados requerem de fundos dessa espécie para seu funcionamento. Segundo dados do Museu em Números, $77,7 \%$ dos museus brasileiros não possuem orçamento próprio.

Muitas vezes, os museus, para ter uma fonte extra de recursos, optam pela criação das Associações de Amigos - parcerias entre o poder público e a sociedade civil. Contudo, outros fatores, além da falta de financiamento, não podem deixar de serem revistos no modelo atual de administração museal. Cita-se, entre eles, a rigidez burocrática, a permanente instabilidade política na gestão e a imobilidade e estabilidade dos empregados públicos, que não possuem incentivos.

Segundo Schuler (2012), há um modelo administrativo brasileiro que tem dado resultado, quando se trata de instituições culturais: a Organização Social (OS). As OS, criadas 
por lei federal número 9.637 em 1998, funcionam como uma gestão compartilhada entre o governo e a sociedade civil; esta, através de organizações culturais privadas sem fins lucrativos, assume a gestão dos equipamentos culturais. A relação é regida por um contrato de metas, regras e valores; as primeiras devem ser alcançadas, e as segundas obedecidas, para que o repasse financeiro se concretize integralmente. Dessa forma, governo e sociedade civil criam um acordo simbiótico, sustentado pelo interesse mútuo na preservação e no fomento do patrimônio cultural.

Assim, ainda de acordo com o autor, com a possibilidade dessa forma de administração jurídica, a instituição ganha autonomia cultural, organizacional e financeira; ou seja, passa de uma gestão voltada aos meios para uma que prioriza os fins. Além disso, esse modelo possibilita a multiplicação das fontes de financiamento através de ferramentas que outrora, sob o modelo burocrático de gestão estatal, não eram possíveis, como: o aluguel dos espaços para eventos, a venda de produtos próprios (loja e café), a venda de ingresso e o aumento do patrocínio direto e das parcerias institucionais. Importante ressaltar que a OS não se trata de privatização e sim publicização, pois não envolve lucro.

\section{O Museu de Arte do Rio de Janeiro}

Criado em 2012, o Museu de Arte do Rio de Janeiro (MAR), é um museu público de arte e cultura visual administrado por uma Organização Social, o Instituto Odeon. Aberto ao público em março de 2013, o MAR faz parte do projeto de revitalização da região portuária do Rio de Janeiro, uma iniciativa da Prefeitura.

Segundo o relatório de gestão de 2013 , o foco da instituição é na educação e aquisição e preservação de acervo, visando a democratização do público, consolidando o museu como um equipamento cultural da cidade. Programas de atendimento às escolas públicas e a capacitação de professores são importantes instrumentos utilizados pelo MAR para a consolidação de sua missão, só possíveis graça a autonomia de gestão.

Apesar da recente abertura, o MAR já possui números invejáveis para qualquer museu brasileiro, são mais de 300 mil visitantes em 2013 e 200 mil em 2014. Além disso, segundo pesquisa da Datafolha a instituição é conhecida por mais de $60 \%$ dos habitantes do Rio de Janeiro ${ }^{7}$.

\footnotetext{
${ }^{7}$ Fonte: Pesquisa Hábitos Culturais dos Cariocas - Instituto Datafolha, Secretaria Municipal de Cultura e J. Leiva Cultura \& Esporte. Outubro de 2013.
} 


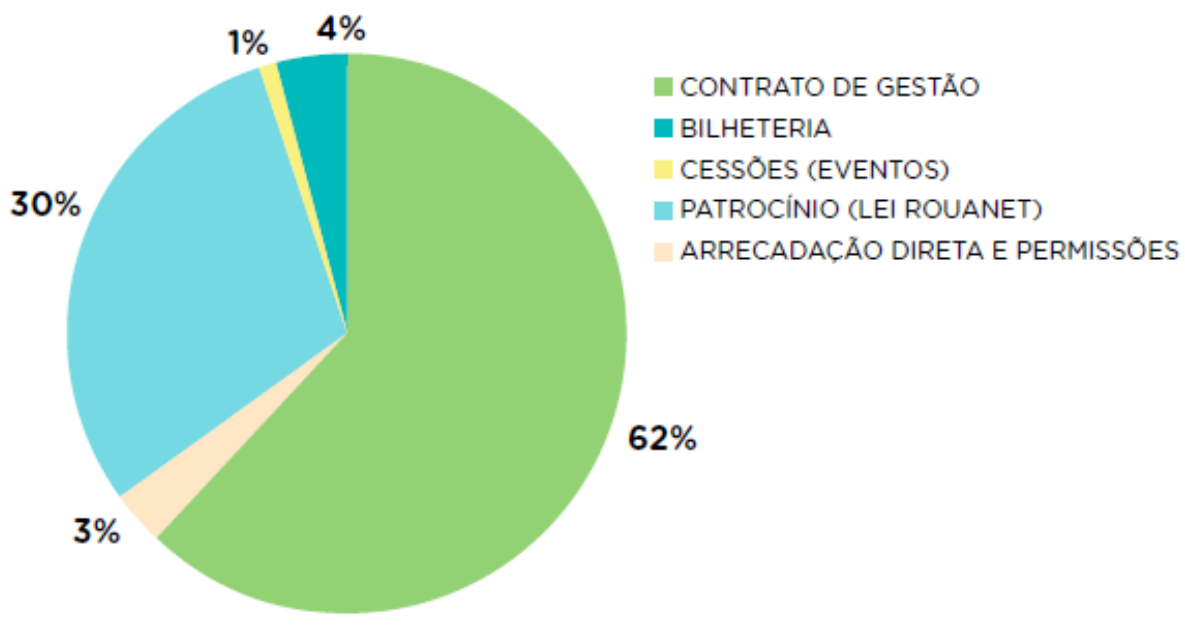

FIGURA 1 - Percentual de fontes orçamentárias MAR FONTE: Relatório de Gestão MAR 2013

Segundo dados do Relatório de Gestão de 2013 é possível identificar as fontes orçamentárias do MAR (FIGURA 1). Apesar da maioria do investimento ainda ser proveniente do poder público - o repasse governamental foi 24 milhões durante os dois anos de gestão e através da captação pelo patrocínio da Lei Rouanet, que aumentou de 5.2 milhões em 2013 para 8.1 milhões no ano seguinte, é interessante observar a porcentagem de recursos provenientes de doações sem incentivos fiscais. Apesar de tímida, na primeira fase em 2014, somaram mais de 88 mil reais.

O repasse governamental, segundo o Relatório de Gestão, dá conta das despesas relativas ao funcionamento e operação do museu. Sendo assim, pode-se afirmar que o restante das fontes orçamentárias - as não-estatais - financiam a manutenção das atividades-fim do MAR, como a programação expositiva e as atividades educativas. Para os próximos anos, segundo a própria instituição, projeta-se um incremento do percentual orçamentário advindo das fontes privadas.

\section{Considerações finais}

Revisando o processo histórico das políticas culturais brasileiras, pode-se compreender a atual situação em que o país se encontra, no que toca as manifestações culturais financiadas pelo Estado. A cultura é ainda um setor que sofre grande influência quanto ao panorama econômico mundial; porém, em meio à crise econômica, os avanços que os últimos governos conquistaram nessa área específica não podem ser esquecidos. A discussão deve continuar crescendo, no sentido da valorização da cultura, da memória e das identidades locais e regionais.

O modelo de gestão através de OS não traz soluções imediatas, mas é um passo 
positivo em direção à desburocratização dos processos de viabilização financeira dos museus. Deve-se desmistificar a concepção de que os brasileiros não se interessam por institutos deste caráter - de que museus são prédios velhos e empoeirados, esquecidos e abandonados por definição. A nova articulação de museus trata-os como espaços vivos e democráticos, e acreditamos que, ampliando-se os escopos de programação, amplia-se a participação do público e, consequentemente, a relevância cultural e ideológica das instituições museológicas para a sociedade.

Artigo recebido em 08/06/2016 Aprovado para publicação em 28/09/2016

\section{Referências}

ABREU, R. M. A cultura do Mecenato: Uma Cultura Possível? In: JUNIOR, José do Nascimento (org.). Economia dos Museus. 1ed. Brasília: MinC/IBRAM, 2010, v. 1, p. 163-203.

BARBALHO, Alexandre. Política Cultural. In: RUBIM, Linda (Org.). Organização e Produção da Cultura. Salvador: Edufba, 2005.

BOTELHO, Isaura. Dimensões da Cultura e Políticas Públicas. São Paulo em Perspectiva. v. 15, n. 2, p. 73-83. abr./jun. 2001.

BRASIL. Constituição (1988). Constituição da República Federativa do Brasil. Brasília, DF: Senado Federal: Centro Gráfico, 1988.

COELHO, Teixeira. Dicionário Crítico de Política Cultural. Cultura e Imaginário. São Paulo: Iluminuras, 1997.

DURAND, José Carlos. Política Cultural e Economia da Cultura. São Paulo: Edições Sesc SP, 2013.

FERNANDES, Natália Morato. A política cultural à época da ditadura militar. Contemporânea. v. 3, n. 1, 2013, p. 173-192. 
INSTITUTO BRASILEIRO DE MUSEUS (IBRAM). Museus em Números. Brasília: Instituto Brasileiro de Museus, 2011; v. 1-2.

. Museus e a dimensão econômica: da cadeia produtiva à gestão sustentável. Brasília: Instituto Brasileiro de Museus, 2014; v. 1.

MAR. Relatório de Gestão 2013 e 2014.

MINC, IPHAN, DEMU. Política nacional de museus: relatório de gestão 2003-2006. Brasília: Ministério da Cultura, Instituto do Patrimônio Histórico e Artístico Nacional, Departamento de Museus e Centros Culturais; 2010. CDD 069.0981

RUBIN, Antônio Albino Canelas. Políticas culturais no Brasil: passado e presente. In: RUBIN, Antonio A. C.; ROC HA, Renata (Orgs.). Políticas culturais. Salvador: EDUFBA, 2012.

SANTOS, Myrian Sepúlveda. Museus Brasileiros e Política Cultural. Revista Brasileira de Ciências Sociais. v. 19, n. 55, 2004, p. 53-73.

SCHÜLER, Fernando Luís. Gestão Cultural: o Desafio da Sustentabilidade e a Alternativa dos Fundos de Endowment. Interfaces Brasil/Canadá. Canoas, v. 12, n. 15, 2012, p. 129-154. 